\title{
The Effects of Hydraulic Properties of Bedrock on the Stability of Slopes
}

\author{
Amin Askarinejad, Patrick Bischof, Francesca Casini, and Sarah M. Springman
}

\begin{abstract}
The transient process of rain infiltration in the soil and the effect of geometry and drainage properties of the bedrock on the pore pressure distribution and the stability of a slope are investigated. The simulated slope is a test field in northern Switzerland, where landslide triggering experiments were carried out. From geological point of view, the experimental site is located in the Swiss Molasse basin. The lithological units in the area are composed of horizontally layered and fractured sandstones intersected by marlstone. The stability of the slope is monitored at different stages of the infiltration using the limit equilibrium method of slices. Several cases were compared to study the effect of the fissures in the shallow bedrock on the stability of the slope. The approximate location and size of the fissures in the bedrock were determined by monitoring of spatial and temporal changes of electrical resistivity during rainfall and also geological investigations of the bedrock before and after the failure.
\end{abstract}

Keywords: bedrock, landslides, unsaturated soils, silty sand, limit equilibrium method, finite element method.

\author{
Amin Askarinejad \\ Institute for Geotechnical Engineering, \\ Swiss Federal Institute of Technology, ETH Zurich, Switzerland \\ email: amin.askarinejad@igt.baug.ethz.ch \\ Patrick Bischof \\ Institute for Geotechnical Engineering, \\ Swiss Federal Institute of Technology, ETH Zurich, Switzerland \\ email: pbischofastudent.ethz.ch \\ Francesca Casini \\ Institute for Geotechnical Engineering, \\ Swiss Federal Institute of Technology, ETH Zurich, Switzerland \\ email: francesca.casiniaigt.baug.ethz.ch \\ Sarah M. Springman \\ Institute for Geotechnical Engineering, \\ Swiss Federal Institute of Technology, ETH Zurich, Switzerland \\ email: sarah.springmandigt.baug.ethz.ch
}




\section{Introduction}

A $38^{\circ}$ steep slope, with an area of $\sim 250 \mathrm{~m}^{2}$, was selected near Ruedlingen (Canton Schaffhausen, Switzerland) where landslide triggering experiments were carried out in autumn 2008 and spring 2009. Some surface movements were detected during the first experiment on the right part of the slope (looking from bottom) after 4.5 days of rainfall with average intensity of $22 \mathrm{~mm} / \mathrm{hr}$. However, failure did not occur. The sprinklers were relocated to provide more intense rainfall to the upper part of the slope, where shallower bedrock and less root reinforcement were expected. The roots were also cut along the longitudinal sides (RHS and LHS, Fig.1) of the slope down to a depth of $40 \mathrm{~cm}$. A failure was triggered in March 2009 on the upper right part of the test field, after 15 hours of artificial rainfall, with average intensity of $12 \mathrm{~mm} / \mathrm{hr}$, mobilising about $130 \mathrm{~m}^{3}$ of debris. The shape of the bedrock position of the sensor clusters and possible location of the fissures in the bedrock are illustrated in Fig. 1. Electrical Resistivity Tomography (ERT) measurements were performed every 1 hour and were analysed by Gambazzi \& Suski (2009) in both experiments.

The transient process of infiltration in the soil profile and the effect of the geometry and draining properties of the bedrock at the lower part of the slope on the pore pressure distribution will be investigated in order to compare the experiments of 2008 and 2009.

The numerical simulations were performed using two modules of GEOSLOPE software. The infiltration process was modelled by using the finite element module of SEEP/W. Afterwards, the stability of the slope will be analysed by SLOPE/W, which is a limit-equilibrium-based slope stability software, based on the pore pressure distribution at different stages of infiltration.

\section{Hydraulic Properties and Simulations}

Ruedlingen soil is characterised as a medium to low plasticity silty sand according to the USCS (Casini et al. 2010). A Water Retention Curve (WRC) of this soil has been obtained from suction controlled laboratory tests (Casini et al. 2010). The wetting branch of this WRC is used for the numerical simulations (Fig. 2). Based on the laboratory tests on undisturbed samples, the saturated hydraulic conductivity was measured to be $K_{\text {sat }}=10^{-7} \mathrm{~m} / \mathrm{s}$ (Springman et al. 2009). A small sample (diameter of $7 \mathrm{~cm}$ and height of $2 \mathrm{~cm}$ ) of soil has been used in these laboratory tests. However, various kinds of heterogeneity, such as root holes, and other macro-pores further complicate the hydrology in reality (Asakrinejad et al. 2012a). Accordingly, the in-situ saturated hydraulic conductivity of $K_{\mathrm{sat}} \approx 10^{-4} \mathrm{~m} / \mathrm{s}$ is determined and implemented in these simulations (Brönnimann 2011, Askarinejad et al. 2012b). The unsaturated hydraulic conductivity of the soil was fitted, based on the approach of van Genuchten (1980) using the $K_{\text {sat }}$ and the WRC. This function is shown in Fig. 3.

The rock mass is assumed to be impermeable and the fissures are "filled" with the same material as the overlying soil. 
The applied rain intensity in the first experiment (October 2008) was higher in the lower half of the slope (below cluster 2, Fig. 1). Accordingly, two rain zones are defined in the model. The sprinklers were relocated in the second experiment (March 2009), and seven zones of rain intensity were defined in the model, with the highest intensity applied at the upper part of the slope (above cluster 3, Fig. 1).

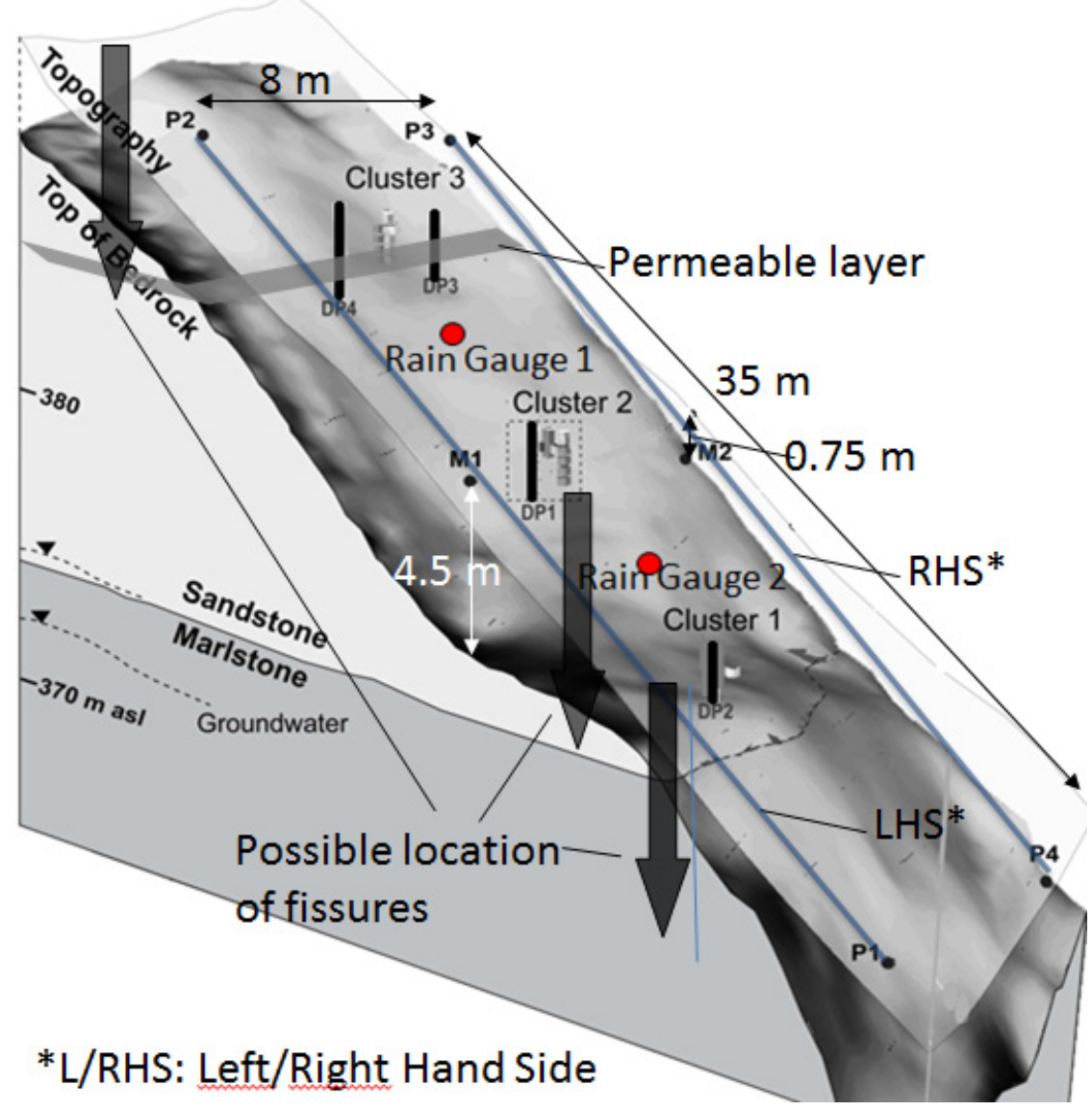

Fig. 1. Shape of the bedrock, position of the sensor clusters, and location of the fissures in the bedrock (after Brönnimann 2011).

\section{Slope Stability Analysis}

The shear strength of the unsaturated soils was applied in SLOPE/W using the approach of Fredlund et al. (1978). Based on this method, an extended form of the Mohr-Coulomb criterion is used:

$$
\tau_{f}=c^{\prime}+\left(\sigma-u_{a}\right) \tan \varphi^{\prime}+\left(u_{a}-u_{u}\right) \tan \varphi^{b}
$$


where, $\varphi^{\mathrm{b}}$ describes the linear increase of the shear strength due to the increase of matric suction. The reinforcement effect of the roots is implemented in the mechanical properties of the model by introducing additional cohesion $\left(\mathrm{c}_{\mathrm{veg}}=4 \mathrm{kPa}\right)$ to the upper $30 \mathrm{~cm}$ of the top soil layer (Schwarz \& Rickli 2008). The mechanical properties used for these simulations are summarised in table 1.

Table 1. Mechanical properties of the overlaying soil.

\begin{tabular}{ccccc}
\hline$\gamma\left(\mathrm{kN} / \mathrm{m}^{3}\right)$ & $\varphi\left(^{\circ}\right)$ & $\varphi^{b}\left({ }^{\circ}\right)$ & $\mathrm{c}^{\prime}\left(\mathrm{kN} / \mathrm{m}^{2}\right)$ & $\mathrm{c}_{\mathrm{veg}}\left(\mathrm{kN} / \mathrm{m}^{2}\right)$ \\
\hline 16.3 & 32 & 10 & 0 & 4 \\
\hline
\end{tabular}

The stability calculations are based on the method of slices using the approach of Morgenstern \& Price (1965).

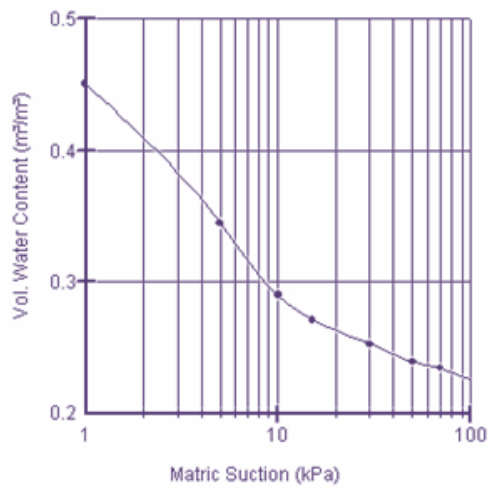

Fig. 2. The wetting branch of WRC of the Ruedlingen soil (Bischof 2010).

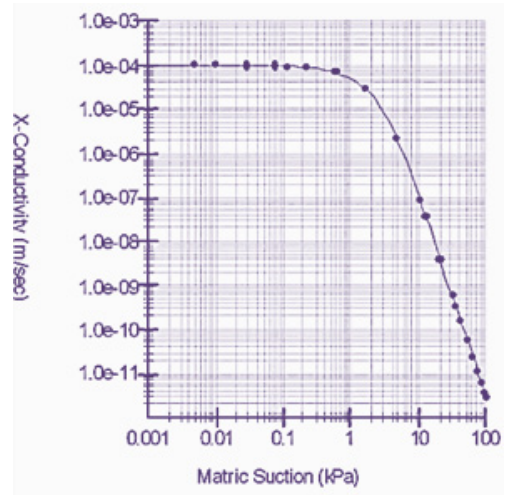

Fig. 3. Hydraulic conductivity function of the Ruedlingen soil (Bischof 2010).

\section{Bedrock Shape and Location of Fissures}

The shape of the bedrock was determined using Dynamic Probing Light (DPL) methods. According to the DPL results, the bedrock is between $0.5 \mathrm{~m}$ to more than $5 \mathrm{~m}$ deep. Bedrock is shallower on the right hand side (RHS, Fig. 1) of the field than on the left side (LHS, Fig. 1). The locations of the fissures were implied from permeability tests performed at different points on the slope, and also by analysis of the Electrical Resistivity Tomography (ERT) during both the experiments (Gambazzi \& Suski 2009). The permeability tests at the lower and in the middle parts of the slope (Clusters 1 and 2, respectively) revealed the existence of large fissures in the bedrock. Moreover, it was observed that water flowed out of the bedrock at the back of the slip surface after the failure. This observation was an indication of the existence of a horizontal permeable layer (Fig. 1), which is 
consistent with the results of the geological investigations (Brönnimann 2011). The hydraulic conductivity of this layer was assumed to be 10 times more than the overlying soil in the numerical simulations. A fissure on the upper part of the slope was interpreted based on the ERT measurements. This fissure conveyed water to the horizontal permeable layer. However the inclination of this fissure is not clear in the ERT measurements. In this series of simulations the effect of the inclination of this top fissure on the stability of the slope is investigated.

\section{Numerical Simulations}

\subsection{Effect of the Fissures in the First Experiment}

The saturated zone and the critical failure surface of the $1^{\text {st }}$ experiment, with and without the fissures in the bedrock, are shown in Fig. 4 and Fig. 5, respectively. The FoS is 0.98 after the artificial rainfall, with "drainage fissures" in the lower part of the slope, according to these simulations. Contrarily, without fissures, the FoS of the critical slip surface is calculated to be equal to 0.16 . It can be concluded that the investigated slope might have failed during the first experiment if there were no "drainage fissures" in the bedrock in the lower part of the slope.

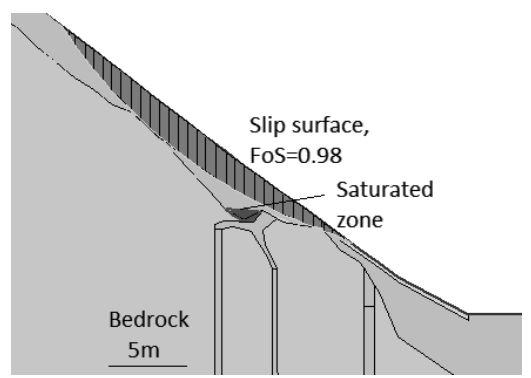

Fig. 4. Critical slip surface in the 1 st experiment, with fissured bedrock (Bischof 2010).

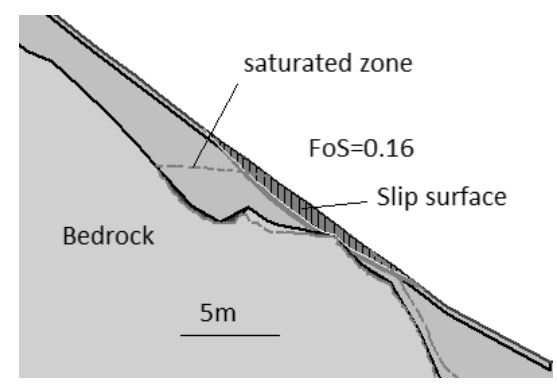

Fig. 5. Critical slip surface in the 1 st experiment, with intact bedrock (Bischof 2010).

\subsection{Simulation of the Second Experiment}

The simulations of the second experiment were conducted on a model with the geometry based on the right hand side of the field, because the failure occurred on this side. The distribution of pore pressure and the flow directions are depicted in Fig. 6. The numerical analyses show that the water applied in zone 7 flows through the fissure in upper part of the slope and then through the horizontal permeable layer. From there, it infiltrates back into the slope body, applying an 
uplifting hydraulic pressure. The majority of the infiltrated water drains through the fissures into the bedrock in the lower part of the slope. The factor of safety after 15 hours of rainfall for the critical slip surface is calculated to be 0.76 . This value is derived from a two dimensional analysis and the frictional resistance of the sides are neglected. Taking these effects into account, the FoS increases to around 1, which is in accordance with the failure in reality (Bischof 2010 and Askarinejad et al. 2012b).

\section{Parametric Study of the Second Experiment and Conclusions}

The changes in the factor of safety are investigated with different bedrock conditions during the application of the rainfall (Fig. 7). The general trend shows that FoS decreases with during the rain and that it recovers when the rain stops. Simulations were performed on models with the bedrock shape of the left hand side and the results show a higher FoS for these models (Fig. 7). The reason for this observation is that the bedrock is deeper on the left hand side compared to the depth of bedrock on the right hand side. The effect of the inclination of the upper fissure was also studied and the results showed a general decrease in the FoS (Fig. 7). However, this decrease in the FoS is not significant. This observation shows that the upper fissure and the horizontal intrusion in the upper part of the slope store the water and, therefore, cause a delay in exfiltration of the water into the slope body. This hypothesis is supported by the simulations of the model with an alternative angle of the inclined fissure (Fig. 6 and Fig. 7)

In conclusion, it was observed that the draining fissures in the bedrock played a major role in stabilising the slope during the first experiment, and the shallower depth of the bedrock and the presence of a permeable layer in the upper part of the slope might have been factors involved in triggering the failure in the $2^{\text {nd }}$ experiment.

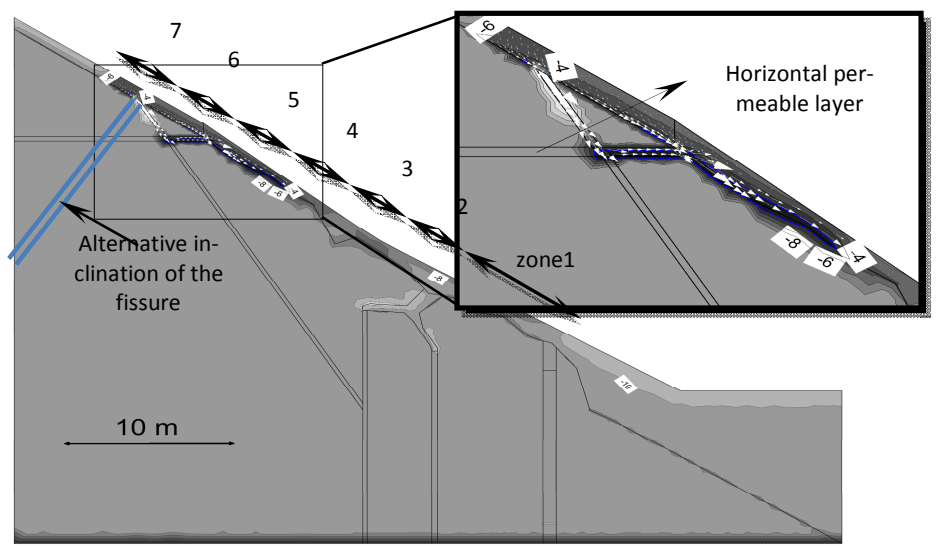

Fig. 6. Pore pressure distribution, the location of exfiltration from the bedrock, and the flow vectors at the end of the second experiment. 


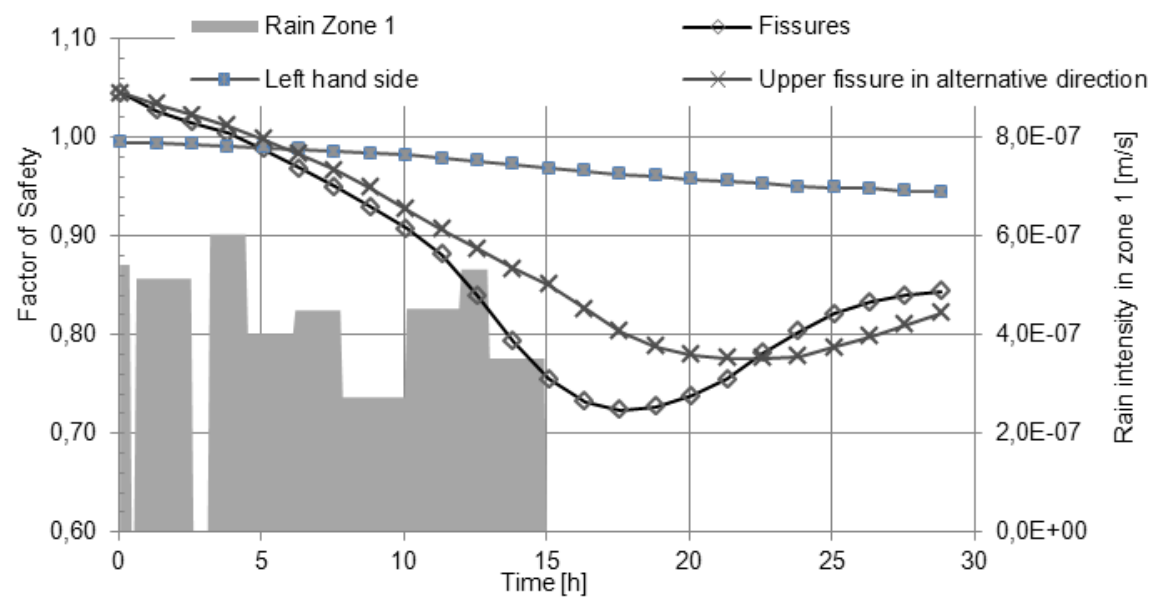

Fig. 7. The changes in the FoS with different bedrock conditions during the $2^{\text {nd }}$ experiment.

Acknowledgements. This research was derived from earlier funding by the Competence Centre for Environment and Sustainability (CCES) within the framework of the Triggering of RApid Mass Movements (TRAMM) - Project.

\section{References}

Askarinejad, A., Beck, A., Casini, F., Springman, S.M.: Unsaturated hydraulic conductivity of a silty sand with the instantaneous profile method. In: Unsaturated Soil: Research and Applications, E-Unsat 2012, Napals (full text submitted, 2012a)

Askarinejad, A., Bischof, P., Beck, A., Casini, F., Springman, S.M.: Rainfall induced instabilities in a silty sand slope: a case history in northern Switzerland. Submitted to RIG (Italian Geotechnical Journal) (2012b)

Bischof, P.: Modelling the interaction of the bedrock and slope in terms of drainage and exfiltration. Institute for Geotechnical Engineering. Swiss Federal Institute of Technology, Zurich (2010) Semester project

Brönnimann, C.: Effects of groundwater on landslide triggering. EPFL, PhD thesis (2011)

Casini, F., Jommi, C., Springman, S.M.: A laboratory investigation on an undisturbed silty sand froma slope prone to landsliding. Granular Matter 12(3), 303-316 (2010)

Fredlund, D.G., Morgenstern, N.R., Widger, R.A.: The shear strength of unsaturated soils. Canadian Geotechnical Journal 15(3), 313-321 (1978)

Gambazzi, F., Suski, B.: Electrical Resistivity Tomography Rüdlingen. Internernal Tramm meeting. ETH Zurich, Switzerland (2009)

Morgenstern, N.R., Price, V.E.: The Analysis of the Stability of General Slip Surfaces. Géotechnique 15, 79-93 (1965)

Schwarz, M., Rickli, C.: Characterisation of the vegetation cover at the test site of Ruedlingen, Internal GEOLEP CCES-TRAMM report (2008)

Springman, S.M., Kienzler, P., Casini, F., Askarinejad, A.: Landslide triggering experiment in a steep forested slope in Switzerland. In: 17th International Conference of Soil Mechanics and Geotechnical Engineering, Alexandria, Egypt, pp. 1698-1701 (2009)

van Genuchten, M.T.: A closed-form equation for predicting the hydraulic conductivity of unsaturated soils. Soil Sci. Soc. Am. J. 44, 892-898 (1980) 